Article

\title{
Paravertebral Muscle Training in Patients with Unstable Spinal Metastases Receiving Palliative Radiotherapy: An Exploratory Randomized Feasibility Trial
}

\author{
Tanja Sprave $^{1, *}$, Friederike Rosenberger ${ }^{2}\left(\mathbb{D}\right.$, Vivek Verma ${ }^{3} \mathbb{D}$, Robert Förster ${ }^{4}\left(\mathbb{D}\right.$, Thomas Bruckner ${ }^{5}(\mathbb{D}$, \\ Ingmar Schlampp ${ }^{6}$, Tilman Bostel ${ }^{7}$, Thomas Welzel ${ }^{6} \mathbb{D}$, Sati Akbaba ${ }^{6}{ }^{\mathbb{D}}$, Tilman Rackwitz ${ }^{6}$, \\ Nils Henrik Nicolay ${ }^{1,8} \mathbb{D}^{D}$, Anca-Ligia Grosu ${ }^{1}$, Joachim Wiskemann ${ }^{2} \mathbb{D}$, Jürgen Debus ${ }^{6,8}$ and \\ Harald Rief ${ }^{9}$ \\ 1 Department of Radiation Oncology, University Hospital of Freiburg, Robert-Koch-Strasse 3, 79106 Freiburg, \\ Germany; nils.nicolay@uniklinik-freiburg.de (N.H.N.); anca.grosu@uniklinik-freiburg.de (A.-L.G.) \\ 2 Department of Medical Oncology, National Center for Tumor Diseases (NCT), Heidelberg University Hospital, \\ 69120 Heidelberg, Germany; friederike.rosenberger@nct-heidelberg.de (F.R.); \\ joachim.wiskemann@nct-heidelberg.de (J.W.) \\ 3 Department of Radiation Oncology, Allegheny General Hospital, Pittsburgh, PA 15212, USA; \\ vivek333@gmail.com \\ 4 Department of Radiation Oncology, University Hospital Zurich, Raemistrasse 100, 8091 Zurich, Switzerland; \\ robert.foerster@usz.ch \\ 5 Department of Medical Biometry, University Hospital of Heidelberg, Im Neuenheimer Feld 305, 69120 Heidelberg, \\ Germany; bruckner@imbi.uni-heidelberg.de \\ 6 Department of Radiation Oncology, Heidelberg Institute of Radiation Oncology (HIRO), Im Neuenheimer \\ Feld 280, 69120 Heidelberg, Germany; ingmar.schlampp@med.uni-heidelberg.de (I.S.); \\ thomas.welzel@med.uni-heidelberg.de (T.W.); sati.akbaba@med.uni-heidelberg.de (S.A.); \\ tilman.rackwitz@med.uni-heidelberg.de (T.R.); juergen.debus@med.uni-heidelberg.de (J.D.) \\ 7 Department of Radiation Oncology, University Medical Center of the Johannes Gutenberg-University Mainz, \\ 55131 Mainz, Germany; tilman.bostel@unimedizin-mainz.de \\ 8 Heidelberg Institute of Radiation Oncology (HIRO), German Cancer Research Center (DKFZ), \\ 69120 Heidelberg, Germany \\ 9 Radiooncological Practice Bad Godesberg, Waldstrasse 73, 53177 Bonn Bad-Godesberg, Germany; \\ harald.rief@gmx.at \\ * Correspondence: tanja.sprave@uniklinik-freiburg.de; Tel.: +49-761-270-94010; Fax: +49-761-270-95820
}

Received: 30 September 2019; Accepted: 5 November 2019; Published: 11 November 2019

\begin{abstract}
Background: Isometric paravertebral muscle training (IPMT) may improve mobility, pain, and quality of life (QOL) in cancer patients with spinal metastases. However, this regimen remains unproven in patients with unstable spinal metastases (USM), a population at high risk for clinical exacerbation with such interventions. Thus, we conducted this exploratory, non-blinded, randomized controlled trial (NCT02847754) to evaluate the safety/feasibility of IPMT and secondarily assess pain, bone density, pathologic fracture rate, and QOL. Methods: All patients had histologically/radiologically confirmed USM (per Taneichi score) and underwent non-operative management with 5-10 fractions of palliative radiotherapy (RT). Randomization (1:1) groups were IPMT (intervention, INT) or muscle relaxation (control, CON); both lasted $15 \mathrm{~min} /$ day and started concurrently with radiotherapy. The primary endpoint was feasibility (completion of training programs three months post-RT). Secondary endpoints were pain response (Visual Analog Scale) and opioid consumption, bone density and pathologic fracture rate, and QOL (European Organization for Research and Treatment of Cancer, EORTC questionnaires). Results: Sixty patients were randomized and 56 received protocol therapy. Mean survival in both groups was 4.4 months. There were no adverse events with either training regimen. Altogether, $\geq 80 \%$ of the planned sessions were completed by $55 \%(n=16 / 29)$ in CON and
\end{abstract}


$67 \%(n=18 / 27)$ in INT. Regarding the post-radiotherapy home-based training, $\geq 80 \%$ of planned sessions were completed by $64 \%(n=9 / 14)$ of the INT cohort. There were no differences in pain scores, opioid consumption, or bone density between arms ( $p>0.05$ for all). No difference was observed between groups regarding new pathological fractures (INT: $n=1$ vs. CON: $n=3$ ) after three months $(p=0.419)$. There were no QOL differences between arms (all parameters $p>0.05$ ). Conclusions: IPMT is potentially feasible for high-risk USM patients. Future trials adequately powered for relevant endpoints are thus recommended.

Keywords: spine metastases; unstable; training; palliative radiotherapy

\section{Introduction}

The spine is a very common area of metastatic disease [1,2]; thus, activities of daily living and quality of life (QOL) can be markedly hampered in these patients. Spinal metastases can be categorized as stable or unstable, based on several factors such as tumor burden and location, symptomatology, and several parameters on imaging [3].

Whereas stable spinal metastases are often treated with palliative radiation therapy (RT) alone, management of unstable spinal metastases (USM) represents an interdisciplinary challenge [4-7]. Although surgical therapy is commonly performed, many patients with metastatic cancer are not surgical candidates for several reasons. Thus, palliative RT remains an effective treatment option for spine instability and pain [8-13]. Conservative treatment often involves patient immobilization, most commonly by utilizing an orthopedic corset or with prolonged bedrest.

In order to improve QOL in cancer patients, numerous short- and long-term effects of targeted physical training measures have been reported, with practical and clinically meaningful improvements in pain and mobility [14-18]. Specifically, additional isometric paravertebral muscle training (IPMT) may allow for strengthening paraspinal muscles and improving mobility, pain, and QOL. In a previous randomized trial for stable spine metastases, IPMT (concomitant with palliative RT) affected some of the aforementioned endpoints and did not increase the pathologic fracture rate [19-23].

Despite these encouraging results, this regimen remains unproven for USM; as a result, most prospective trials in this population remain reluctant to implement such interventions, since IPMT in this high-risk population could lead to clinical exacerbation, including increasing the risk of pathologic fracture.

To address this knowledge gap, we conducted this exploratory randomized study, the first of its kind to date, to evaluate the feasibility of IPMT (as compared to muscle relaxation) and secondarily determine effects on pain, bone density, pathologic fracture rate, and quality of life [24].

\section{Materials and Methods}

\subsection{Design and Patient Population}

This exploratory randomized controlled trial (NCT02847754) was approved by the Heidelberg University Independent Ethics Committee (S-223/2016) (Table S1). The goal of this study was to evaluate the feasibility of paravertebral muscle-training exercises (interventional group, INT), as compared to muscle relaxation (control group, CON), in patients with USM receiving palliative RT [24]. The randomization procedure was carried out by a central office; a block randomization approach (block size of 6 ) was utilized.

From December 2016 to November 2018, 60 patients with histologically confirmed cancer and USM of the thoracolumbar segments were considered for this study. USM was defined based on computed tomography (CT) and/or magnetic resonance imaging (MRI) assessment based on the well-recognized Taneichi score $[19,22,25]$. Surgical intervention to the area of USM was not allowed, mainly because the degree and extent of surgical intervention (based on tumor location) would add 
a major confounding factor regarding the ability to postoperatively perform paravertebral muscle training exercises in a uniform time frame. As such, this study included inoperable cases (secondary to disease extent, or medical contraindications) as well as subjects who refused surgery.

Other inclusion criteria were ages 18-80 years, Karnofsky performance score $\geq 70$, ability to provide written informed consent, and an established indication for palliative RT. In order to address potential confounding by bisphosphonates or anti-RANKL agents, one of these compounds was required to be delivered if the patient was not already receiving one such agent. Exclusion criteria were previous RT or surgery to the given irradiation site, spinal cord compression according to the Bilsky score, myeloma/lymphoma histology, involvement of the cervical spine, and/or inability/refusal to complete the given exercise regimen.

\subsection{Interventions}

Complete details of IPMT (INT group) are presented elsewhere [24]. Briefly, these consisted of exercises (1:1 supervised by exercise physiologists or physical therapists) performed once daily, starting on the first day of palliative RT and continuing for the entire RT period. Following RT completion, subjects continued the same exercises three times per week (corroborated by a daily log) in a home-based manner for another three months. The overall exercise regimen was estimated to take 15 min per day and consisted of isometric exercises in four positions: "all fours" (each extremity stretched separately), "plank", "swimming" (toes kept on the floor), and upright with an elastic band tightened in front of the trunk. The holding time for each position was $20 \mathrm{~s}$ initially, and increased from session to session when feasible. The exercises were performed without a corset.

Muscle relaxation (CON group) was also performed for an estimated $15 \mathrm{~min}$ (once daily) during palliative RT as above. These exercises comprised of progressive muscle relaxation for the face, arms, abdomen, and legs. The back was excluded to avoid training effects on the paravertebral muscles. Muscle relaxation was similarly performed with 1:1 supervision and could voluntarily be continued following completion of RT (corroborated by an audio CD).

Palliative RT was delivered in either three-dimensional conformal (3DCRT) or intensity-modulated (IMRT) techniques. Stereotactic body radiation therapy (SBRT) was not allowed for this study. For both techniques, the involved vertebra was treated to a dose of $20 \mathrm{~Gy}$ in 5 fractions or $30 \mathrm{~Gy}$ in 10 fractions. If IMRT was utilized, simultaneous integrated boosting (SIB) was allowed to $30 \mathrm{~Gy}$ for a 5-fraction regimen and $40 \mathrm{~Gy}$ for a 10-fraction regimen. Treatment planning was based on parameters in the Radiation Therapy Oncology Group (RTOG) 0631 study [26] and QUANTEC [27] recommendations. Position verification was carried out weekly before radiotherapy by kilovoltage cone-beam CT and before each fraction by orthogonal portal images being compared with digitally reconstructed radiographs from the planning $\mathrm{CT}$.

\subsection{Endpoints}

Both the primary and secondary endpoint-related parameters were measured at the start of $\mathrm{RT}\left(\mathrm{t}_{0}\right)$, the end of RT $\left(\mathrm{t}_{1}\right)$, three months post-RT $\left(\mathrm{t}_{2}\right)$, and 6 months post-RT $\left(\mathrm{t}_{3}\right)$. During therapy, the treating clinicians documented these parameters, but diaries were used to document patient-reported information subsequently.

Because performing IPMT for USM risks clinical exacerbation (including increasing the risk of pathologic fracture) the primary endpoint of this randomized investigation was feasibility, which referred to completion of the training program at three months following the end of RT. The total number of completed and aborted/canceled training units and adverse events during training was recorded.

The initial secondary endpoint was the pain score, as measured by the Visual Analog Scale (VAS). Pain level was measured by subjective patient reporting on the VAS scale with a range of 0-100. During clinical examination by the study physician, neuropathic pain was also monitored, as well as pain medication usage (opioid usage was converted into an oral morphine equivalent dose (OMED); non-opioid analgesics were also recorded). 
Additional secondary endpoints were bone density and pathologic fracture rate. Bone density was assessed in the irradiated (and unirradiated) vertebral bodies by a single physician with CT imaging (Siemens Somatom Sensation Open, Siemens, Erlangen, Germany) and Syngo Osteo CT workstation in manually selected regions of interest; Hounsfield units were used for bone density measurements. Pathologic fractures were diagnosed by means of CT and/or MRI imaging and comparing to baseline imaging tests. New fractures were, by definition, not present on initial imaging, whereas progressive fractures referred to visibly increasing size and/or number of fracture gaps, dislocation of fracture fragments, or increasing sintering of the compression fracture (if applicable).

The final secondary endpoint was QOL, assessed using the EORTC QLQ BM22 questionnaire, specially designed for patients with bone metastases. This module (range 0-100) comprises of 22 items and four scales for the measurement of pain in various parts of the body (painful sites), pain characteristics (persistent pain, recurrent pain), functional impairment (occurrence of pain when performing different activities, interference with everyday activities), and psychosocial aspects (family, worries, hope) [28]. Fatigue was assessed using the EORTC QLQ FA13 (range 0-100) module, encompassing 13 items and five scales for measuring cancer-related fatigue [29], with subscales covering physical fatigue, emotional fatigue, cognitive fatigue, interference with daily life, and social sequelae. Emotional distress was assessed using the QSC-R10 (range 0-50) questionnaire, which is a reliable questionnaire for determining emotional distress and anxiety in cancer patients [30].

\subsection{Statistical Analysis}

Owing to the exploratory nature of this trial and lack of literature-based reference values, a complete power calculation was not possible; however, with 30 patients in each group, it was possible to detect a standardized mean-value effect of 0.8 with $80 \%$ power at a significance level of 0.05 [24].

All statistical analyses were done using SAS software Version 9.4 or higher (SAS Institute, Cary, NC, USA). All variables were analyzed descriptively by tabulation of the measures of the empirical distributions. According to the scale level of the variables, means and standard deviations (SD) or absolute/relative frequencies, respectively, were reported. Additionally, for variables with longitudinal measurements, the time courses of individual patients were summarized by treatment groups. Descriptive $p$-values of the corresponding statistical tests comparing the treatment groups were reported. The VAS was adjusted for concurrent medications. Analysis of covariance (ANOVA) with repeated measurements, with treatment group as a factor, and pain medication as a covariate, were done. The Wilcoxon signed-rank test was used to detect possible differences between groups after 3 and 6 months. Graphical visualization includes the mean course over time. Finally, we compared the groups for overall survival, using Kaplan-Meier estimates and log-rank tests. Overall survival (OS) was defined as time from randomization until death, or censored at last contact.

\section{Results}

\subsection{Patient Details}

Sixty patients were randomized, and 56 patients started on protocol-based management (Figure 1). One patient (CON) was removed for rapid clinical deterioration from cancer progression, one (INT) for new-onset jugular vein thrombosis, one (INT) for withdrawal of consent, and the final (INT) for severe motion-dependent therapy-resistant pain symptoms.

Baseline characteristics were balanced between the two arms (Table 1). Most patients had thoracic spine disease, and statistical similarities were noted regarding the location of distant metastases, oncologic therapy, and pain medication utilization ( $p>0.20$ for all). Of note, ten patients in the INT cohort and 14 subjects in the CON group initially wore an orthopedic corset $(p=0.396)$. Additionally of note, the Spinal Neoplastic Instability Score (SINS) [3] in INT was significantly higher as compared to CON (12.0 vs. $10.3, p=0.007)$, whereas the Mizumoto score was similar (5.0 vs. 5.5, $p=0.260$ ). 


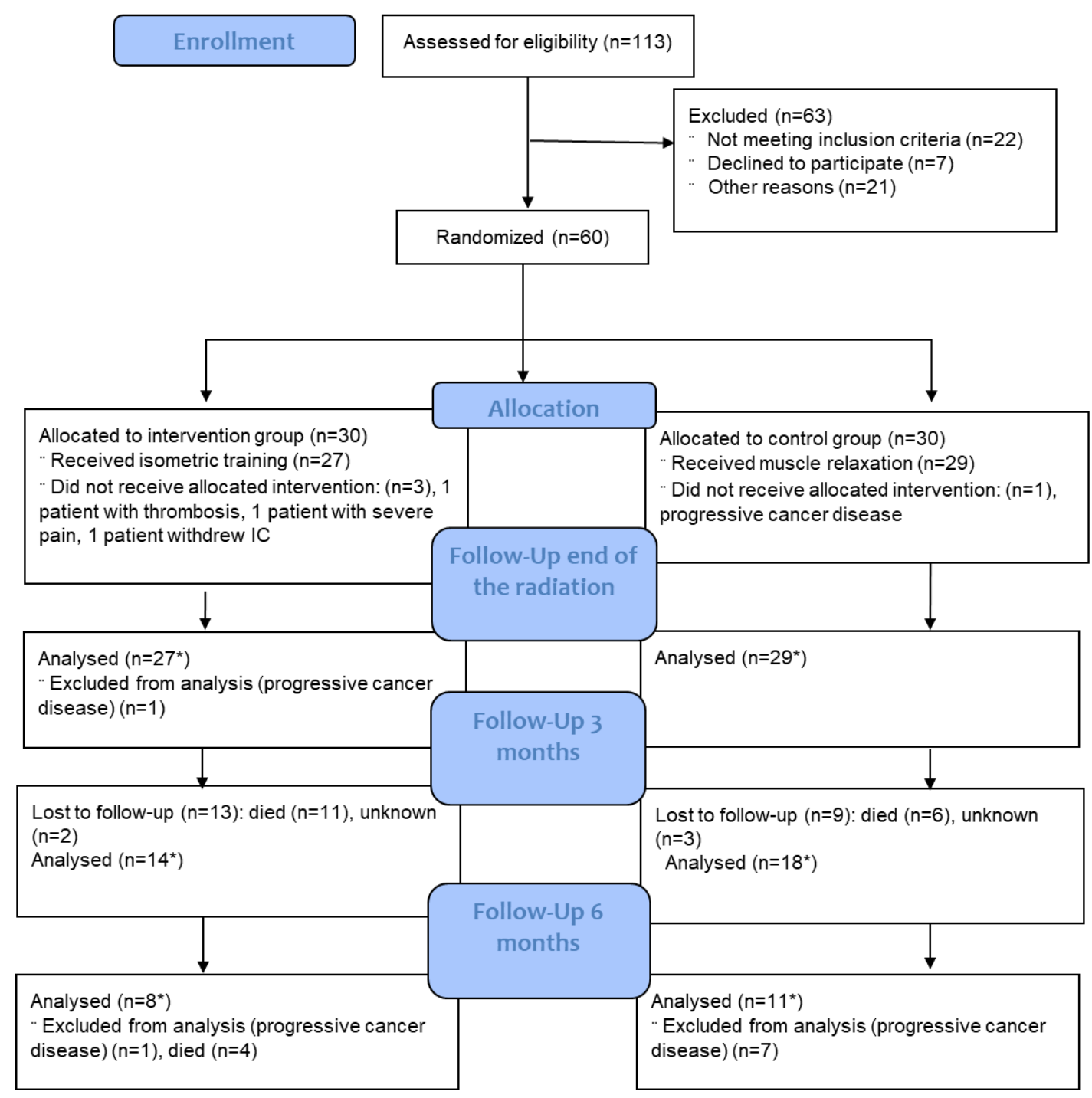

Figure 1. Patient flow through the study. Explanation: * number can differ depending on endpoint, because in some cases individual questionnaires were not collected.

Table 1. Demographics. Baseline characteristics of randomly assigned participants.

\begin{tabular}{ccccc}
\hline & \multicolumn{2}{c}{$\begin{array}{c}\text { Intervention Group } \\
\mathbf{n = 2 7}\end{array}$} & $\begin{array}{c}\text { Control Group } \\
\mathbf{n = 2 9}\end{array}$ & \multirow{2}{*}{-Value } \\
\cline { 2 - 5 } & $\mathbf{n}$ & $\mathbf{\%}$ & $\mathbf{n}$ & $\mathbf{\%}$ \\
\hline Age (years, mean SD) & $62.1(8.8)$ & & $61.1(8.5)$ & 0.724 \\
\hline Gender & & & 12 & 0.611 \\
\hline Male & 13 & 48.1 & 41.4 & \\
\hline Female & 14 & 51.9 & 17 & 58.6 \\
\hline Weight (kg, mean SD) & $71.5(11.3)$ & & $75.1(15.4)$ & 0.337 \\
\hline Height (cm, mean SD) & $172.2(8.6)$ & & $170.4(9.0)$ & 0.426 \\
\hline Body mass index (BMI, mean SD, $\left.\mathrm{kg} / \mathrm{m}^{2}\right)$ & $24.4(4.1)$ & & $25.8(4.6)$ & 0.260 \\
\hline
\end{tabular}


Table 1. Cont.

\begin{tabular}{|c|c|c|c|c|c|}
\hline & \multicolumn{2}{|c|}{$\begin{array}{l}\text { Intervention Group } \\
n=27\end{array}$} & \multicolumn{2}{|c|}{$\begin{array}{c}\text { Control Group } \\
n=29\end{array}$} & \multirow[t]{2}{*}{$p$-Value } \\
\hline & $\mathbf{n}$ & $\%$ & $\mathbf{n}$ & $\%$ & \\
\hline Primary site & & & & & 0.654 \\
\hline Lung cancer & 8 & 29.6 & 14 & 48.3 & \\
\hline Breast cancer & 7 & 25.9 & 6 & 20.7 & \\
\hline Prostate cancer & 4 & 14.8 & 2 & 6.9 & \\
\hline Other & 8 & 29.7 & 3 & 24.1 & \\
\hline Localization metastases & & & & & 0.423 \\
\hline Thoracic & 20 & 74.1 & 24 & 82.8 & \\
\hline Lumbar & 7 & 25.9 & 5 & 17.2 & \\
\hline \multicolumn{6}{|l|}{ Distant metastases at baseline } \\
\hline Viszeral & 9 & 33.3 & 13 & 44.8 & 0.379 \\
\hline Lung & 5 & 18.5 & 11 & 37.9 .1 & 0.108 \\
\hline Brain & 7 & 25.9 & 5 & 17.2 & 0.423 \\
\hline Soft tissue & 2 & 7.4 & 7 & 24.1 & 0.089 \\
\hline Hormontherapy & 9 & 33.3 & 6 & 20.7 & 0.286 \\
\hline Immunotherapy & 12 & 44.4 & 13 & 44.8 & 0.977 \\
\hline Chemotherapy & 19 & 70.4 & 21 & 72.4 & 0.866 \\
\hline Surgery & 15 & 55.6 & 12 & 41.4 & 0.289 \\
\hline Bisphosphonate at baseline & 11 & 40.7 & 14 & 48.3 & 0.571 \\
\hline Orthopedic corset at baseline & 10 & 37.0 & 14 & 48.3 & 0.396 \\
\hline Mizumoto-Score (mean, SD) & $5.0(2.0)$ & & $5.5(1.7)$ & & 0.260 \\
\hline SINS-Score (mean, SD) & $12.0(2.5)$ & & $10.3(2.2)$ & & 0.007 \\
\hline \multicolumn{6}{|l|}{ Medication at baseline } \\
\hline Sleeping medication & 4 & 14.8 & 9 & 31.0 & 0.151 \\
\hline Psychiatric medication & 8 & 29.6 & 8 & 27.6 & 0.866 \\
\hline Dexamethasone & 5 & 18.5 & 2 & 6.9 & 0.189 \\
\hline Opiate & 15 & 55.6 & 16 & 55.2 & 0.977 \\
\hline NSAID & 20 & 74.1 & 22 & 75.9 & 0.877 \\
\hline Inpatient stay & 13 & 48.1 & 11 & 37.9 & 0.440 \\
\hline
\end{tabular}

Abbreviation: SD: standard deviation; SINS: spinal instability neoplastic score; others: adenoid cystic carcinoma, carcinoma of unknown primary (CUP), gastrointestinal stroma tumor (GIST), melanoma, mesothelioma, pancreatic cancer, renal cancer, thyroid cancer, urothelial carcinoma.

The median follow-up was not yet achieved in both arms. Eleven patients $(40.7 \%)$ in the INT group died of disease within three months of RT, versus six patients $(20.7 \%)$ in the CON group. The mean OS was 4.4 months for both groups $(p=0.839)$ (Figure 2). 


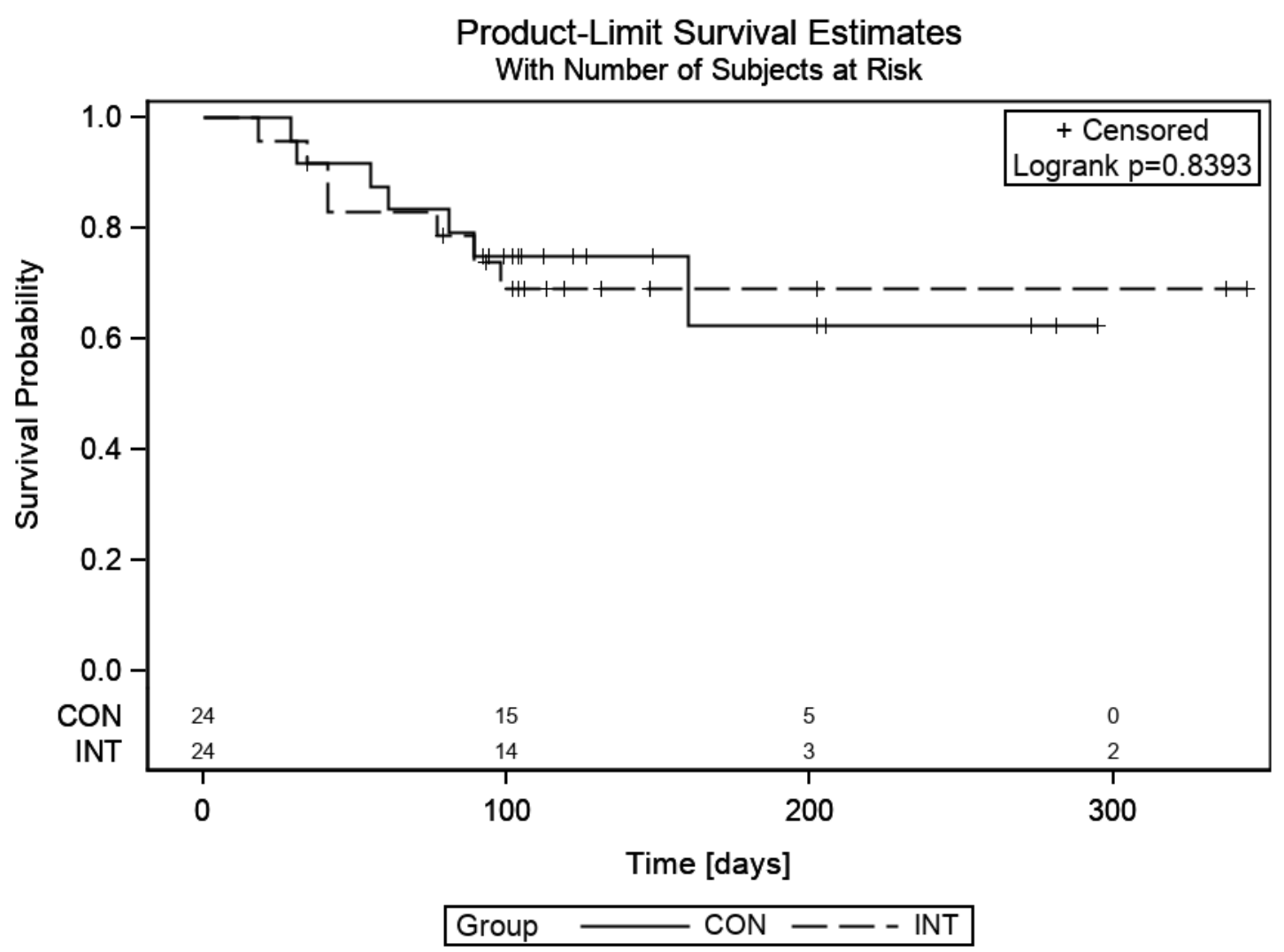

Figure 2. Overall survival of both arms, time in days.

\subsection{Tolerance of Therapy/Feasibility}

RT was altogether tolerated well. No patient in either arm experienced grade $\geq 3$ acute or late events according to the Common Terminology Criteria for Adverse Events v.4.03.

During the supervised training $\left(t_{0}-t_{1}\right)$ there were no adverse events with protocol therapy. In the CON arm, 16 patients ( $55 \%$ ) completed $\geq 80 \%$ of the planned relaxation sessions; the remainder were unable owing to deterioration in the general condition or clinical (non-protocol-related) complications. In INT, $18(67 \%)$ patients completed $\geq 80 \%$ of the planned training sessions. The mean total number of completed training units was 7.8 (SD 3.3), and the mean number of potentially feasible units was 10.1 (SD 2.1).

Similarly, no adverse side effects were reported during post-radiotherapy home-based training $\left(t_{1}-t_{2}\right)$. The specified number of home training sessions was 36 ( $3 \times$ weekly over 12 weeks). In the INT arm, 14 participants were lost to follow-up during the period of $t_{1}-t_{2}$; of these subjects, 11 died and 3 were unknown. From $t_{1}$ to $t_{2}, \geq 80 \%$ of planned sessions were completed by $64 \%$ (9/14) of patients. In INT, 14 analyzed participants completed 39.6 (SD 21.1) of the prescribed 36 training sessions.

\subsection{Pain Response}

No difference in pain response was observed between the two groups after 3 and 6 months (Table 2).

There were also no differences in OMED consumption at the end of RT $\left(t_{1}\right)(p=0.958)$ and three months $\left(t_{2}\right)$ following RT ( $\left.p=0.666\right)$. There were no statistical differences in neuropathic pain between both arms at $3(p=0.826)$ or 6 months $(p=0.965)$. 
Table 2. Pain levels using the Visual Analogue Scale (VAS) at respective points in time of survey in both groups.

\begin{tabular}{cccccccc}
\hline & & \multicolumn{2}{c}{ Intervention Group $\mathbf{n}=\mathbf{2 7}$} & \multicolumn{2}{c}{ Control Group $\mathbf{n}=\mathbf{2 9}$} & $p$-Value \\
\hline VAS & $\mathrm{n}$ & mean & SD & $\mathrm{n}$ & mean & SD & \\
\hline Baseline & 27 & 41.3 & 29.6 & 29 & 44.3 & 29.3 & 0.665 \\
\hline $\begin{array}{c}\text { End of } \\
\text { radiotherapy }\end{array}$ & 26 & 30.6 & 19.7 & 29 & 29.1 & 24.8 & 0.659 \\
\hline 3 months & 14 & 25.4 & 15.5 & 18 & 28.3 & 26.6 & 1.000 \\
\hline 6 months & 7 & 24.3 & 18.1 & 9 & 25.0 & 26.1 & 0.830 \\
\hline \multicolumn{7}{c}{ Abbreviation: VAS: visual analog scale. }
\end{tabular}

The covariance analysis of the OMED consumption in the period $t_{0}-t_{2}$ showed no significant influence on pain level $(p=0.120)$. The covariate evaluation of the interaction between group and time showed no significance, because the temporal changes were parallel $(p=0.970)$. Also, the group effect was not significant $(p=0.316)$. The pain response in the period $t_{0}-t_{2}$ showed a clear temporal dependence $(p=0.009)$ (Figure 3).

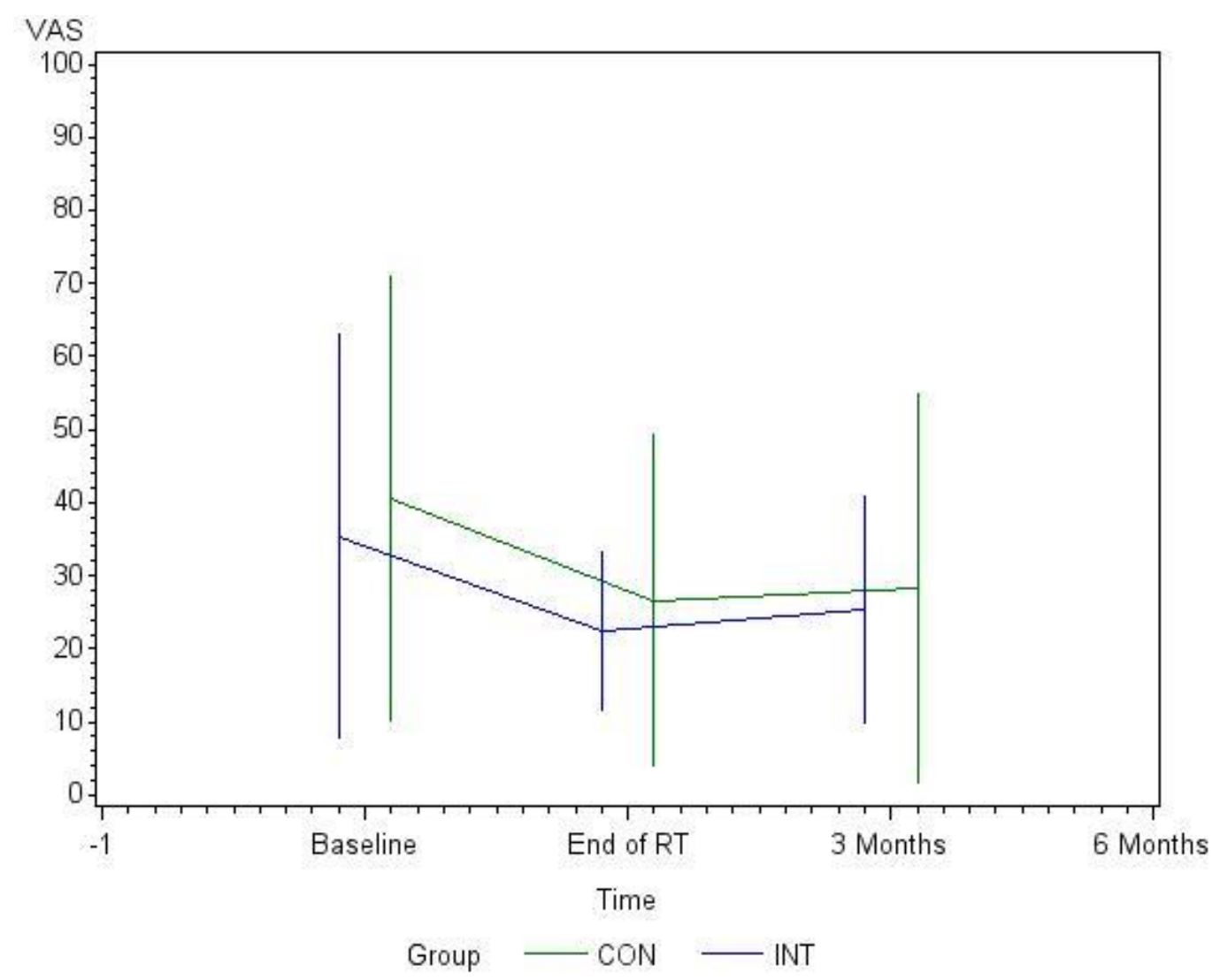

Figure 3. Graphical representation of pain levels using the Visual Analogue Scale (VAS) during the observation period in both groups.

\subsection{Bone Density and Pathologic Fractures}

There were no differences in bone density between arms at $3(p=0.826)$ or 6 months following RT completion $(p=0.965)$. Within the CON group, from $t_{0}$ to $t_{2}$ there was a significant increase in bone density $(p=0.006)$ (Table 3$)$. 
Table 3. These results demonstrate the bone density (HU = Hounsfield units) in metastatic bone before RT (baseline), three and six months after RT. The results were presented by absolute and relative values (\%) of HU within and between group as median (Hodges-Lehmann estimate) and IQR.

\begin{tabular}{|c|c|c|c|c|c|c|c|c|c|c|c|}
\hline & \multicolumn{2}{|c|}{$\begin{array}{l}\text { Intervention } \\
\text { Group }\end{array}$} & \multirow[b]{2}{*}{ IQR } & \multirow{2}{*}{$\begin{array}{l}\text { Within } \\
\text { Group } \\
p \text {-Value }\end{array}$} & \multirow{2}{*}{$\begin{array}{l}\text { Control } \\
\text { Group }\end{array}$} & \multirow[b]{2}{*}{ Median } & \multirow[b]{2}{*}{ IQR } & \multirow{2}{*}{$\begin{array}{l}\text { Within } \\
\text { Group } \\
p \text {-Value }\end{array}$} & \multicolumn{2}{|c|}{$\begin{array}{c}\text { Differences } \\
\text { between Groups }\end{array}$} & \multirow[b]{2}{*}{$p$-Value } \\
\hline & $\mathrm{n}$ & Median & & & & & & & HL & $95 \%$ CI & \\
\hline HU Baseline & 25 & 200.0 & $136.0-240.0$ & & 29 & 168.0 & $139.0-268.0$ & & -3.0 & $-57.0-47.0$ & 0.903 \\
\hline HU T2 & 13 & 278.0 & $215.0-380.0$ & & 18 & 219.5 & $137.0-385.0$ & & 47.5 & $-63.0-150.0$ & 0.378 \\
\hline \multicolumn{12}{|l|}{3 months } \\
\hline HU T0-T2 & 13 & 1.00 & $-18.0-190.0$ & 0.350 & 18 & 30.5 & $-9.0-70.0$ & 0.101 & 5.5 & $-48.0-154.0$ & 0.826 \\
\hline HU T0-T2 (\%) & 13 & 0.38 & $-7.5-118.0$ & 0.491 & 18 & 19.0 & $-7.3-31.7$ & 0.060 & 3.2 & $-26.0-82.1$ & 0.674 \\
\hline \multicolumn{12}{|l|}{6 months } \\
\hline HU T0-T3 & 8 & 111.5 & $-23.5-268.5$ & 0.219 & 10 & 99.5 & $69.0-175.0$ & 0.006 & -2.0 & $-137.0-190.0$ & 0.965 \\
\hline HU Baseline & 10 & 128.5 & $108.0-192.0$ & & 15 & 153.0 & $124.0-173.0$ & & -17.5 & $-59.0-32.0$ & 0.506 \\
\hline HU T2 & 4 & 268.0 & $160.5-365.5$ & & 6 & 196.0 & $112.0-238.0$ & & 56.5 & $-210.0-268.0$ & 0.749 \\
\hline HU T3 & 3 & 380.0 & $136.0-384.0$ & & 5 & 237.0 & $217.0-323.0$ & & 57.0 & $-238.0-178.0$ & 0.551 \\
\hline \multicolumn{12}{|l|}{3 months } \\
\hline HU T0-T2 & 4 & 95.0 & $-7.5-224.5$ & 0.500 & 6 & 32.0 & $-31.0-43.0$ & 0.469 & 81.5 & $-70.0-290.0$ & 0.456 \\
\hline HU T0-T2 (\%) & 4 & 59.0 & $-3.7-166.0$ & 0.500 & 6 & 25.4 & $-7.3-33.3$ & 0.312 & 53.6 & $-41.7-221.3$ & 0.594 \\
\hline \multicolumn{12}{|l|}{6 months } \\
\hline HU T0-T3 & 3 & 223.0 & $0.0-259.0$ & 0.500 & 5 & 78.0 & $69.0-122.0$ & 0.125 & 101.0 & $-175.0-311.0$ & 0.371 \\
\hline HU T0-T2 & 9 & 1.00 & $-18.0-187.0$ & 0.476 & 12 & 16.0 & $-7.0-107.5$ & 0.266 & -9.0 & $-79.0-163.0$ & 0.804 \\
\hline HU T0-T2 (\%) & 9 & 0.38 & $-7.7-71.6$ & 0.652 & 12 & 7.9 & $-5.6-31.4$ & 0.204 & 0.6 & $-31.3-72.0$ & 0.972 \\
\hline \multicolumn{12}{|l|}{6 months } \\
\hline HU T0-T3 & 5 & -15.0 & $-32.0-278.0$ & 0.812 & 5 & 114.0 & $85.0-260.0$ & 0.062 & -82.0 & $-310.0-227.0$ & 0.531 \\
\hline HU T0-T3 (\%) & 5 & -5.7 & $-12.4-135.6$ & 0.812 & 5 & 43.5 & $19.4-115.6$ & 0.062 & -31.7 & $-128.2-116.2$ & 0.676 \\
\hline
\end{tabular}

Abbreviations: $\mathrm{HU}=$ Hounsfield units, $\mathrm{IQR}=$ interquartile range, $\mathrm{T}_{0}=$ baseline, $\mathrm{T}_{2}=3$ months, $\mathrm{T}_{3}=6$ months, $\mathrm{T}_{0}-\mathrm{T}_{2}=$ difference baseline minus 3 months, $\mathrm{T}_{0}-\mathrm{T}_{3}=$ difference baseline minus 6 months. HL = Hodges-Lehmann estimator, $95 \% \mathrm{CI}=95 \%$ Confidence Interval.

At initial presentation, there was a trend towards more pathologic fractures in the INT arm ( $\mathrm{n}=17,63 \%$ vs. CON: $\mathrm{n}=11,39 \%, p=0.079$ ). No pathologic fractures in either arm were de novo; $1 / 14$ and $3 / 18$ cases were progressive in INT and CON, respectively $(p=0.419)$. There were no differences at 6 months $(p=0.243)$. Of note, no cases of salvage surgery for pathologic fractures were necessary in either arm.

Additionally, there did not seem to be differences in 3-month pathologic fractures based on use of an orthopedic corset $(31 \%$ vs. $35 \%, p=0.673)$.

\subsection{Quality of Life}

In the INT group, the QOL parameter specifically for contemplation of painful sites had improved from initial presentation to the end of RT $(p=0.050)$, with a further positive trend between 3 and 
6 months $(p=0.057)$. However, there was no evidence of treatment effect between $\mathrm{t}_{0}-\mathrm{t}_{2}(p=0.478)$ or $\mathrm{t}_{0}-\mathrm{t}_{3}(p=0.753)$ (Tables 4-6).

Table 4. Effects on QOL (EORTC QLQ-BM 22) questionnaire.

\begin{tabular}{|c|c|c|c|c|c|c|}
\hline \multicolumn{7}{|l|}{ Symptom Scales } \\
\hline & \multicolumn{2}{|c|}{ Intervention Group } & \multicolumn{3}{|c|}{ Control Group } & \multirow[b]{2}{*}{ SD } \\
\hline Painful sites & $\mathrm{n}$ & mean & SD & $\mathrm{n}$ & mean & \\
\hline End of radiotherapy $(\mathrm{t} 1)$ & 26 & 29.5 & 19.5 & 29 & 20.7 & 20.3 \\
\hline 3 months (t2) & 14 & 27.6 & 19.9 & 18 & 22.2 & 13.9 \\
\hline 6 months (t3) & 7 & 32.4 & 18.4 & 9 & 17.8 & 14.1 \\
\hline \multicolumn{7}{|c|}{$\begin{array}{l}\text { Treatment effect }(\mathrm{t} 0-\mathrm{t} 2) \text { after } 3 \text { months } p=0.478 \text {, (t0-t3) after } 6 \text { months } p=0.753 \\
\text { Effect size }(\mathrm{t} 0-\mathrm{t} 2) \text { after } 3 \text { months }-5.9 \text {, (t0-t3) after } 6 \text { months } 4.7 \\
\text { Pain characteristics }\end{array}$} \\
\hline End of radiotherapy (t1) & 26 & 44.9 & 28.4 & 29 & 36.0 & 32.6 \\
\hline 3 months (t2) & 14 & 30.2 & 28.7 & 18 & 29.5 & 28.3 \\
\hline 6 months (t3) & 7 & 22.2 & 22.2 & 9 & 23.5 & 26.3 \\
\hline \multicolumn{7}{|c|}{$\begin{array}{l}\text { Treatment effect }(\mathrm{t} 0-\mathrm{t} 2) \text { after } 3 \text { months } p=0.813 \text {, ( } \mathrm{t} 0-\mathrm{t} 3) \text { after } 6 \text { mon } \\
\text { Effect size }(\mathrm{t} 0-\mathrm{t} 2) \text { after } 3 \text { months }-2.6 \text {, }(\mathrm{t} 0-\mathrm{t} 3) \text { after } 6 \text { months }-10.8 \\
\text { Functional } \\
\text { interference }\end{array}$} \\
\hline End of radiotherapy (t1) & 26 & 44.6 & 24.6 & 29 & 36.2 & 22.6 \\
\hline 3 months (t2) & 14 & 37.8 & 29.3 & 18 & 28.5 & 18.7 \\
\hline 6 months (t3) & 7 & 28.6 & 26.8 & 9 & 31.9 & 19.8 \\
\hline \multicolumn{7}{|c|}{$\begin{array}{l}\text { Treatment effect }(\mathrm{t} 0-\mathrm{t} 2) \text { after } 3 \text { months } p=0.611 \text {, }(\mathrm{t} 0-\mathrm{t} 3) \text { after } 6 \text { months } p=0.269 \\
\text { Effect size }(\mathrm{t} 0-\mathrm{t} 2) \text { after } 3 \text { months }-3.8,(\mathrm{t} 0-\mathrm{t} 3) \text { after } 6 \text { months }-9.9 \\
\text { Psychosocial aspects }\end{array}$} \\
\hline End of radiotherapy (t1) & 26 & 58.5 & 17.5 & 29 & 50.4 & 18.1 \\
\hline 3 months ( $\mathrm{t} 2)$ & 14 & 52.4 & 20.8 & 18 & 52.2 & 18.6 \\
\hline 6 months (t3) & 7 & 42.9 & 23.3 & 9 & 51.2 & 21.5 \\
\hline
\end{tabular}

Table 5. Effects on fatigue according to EORTC QLQ-FA 13 questionnaire.

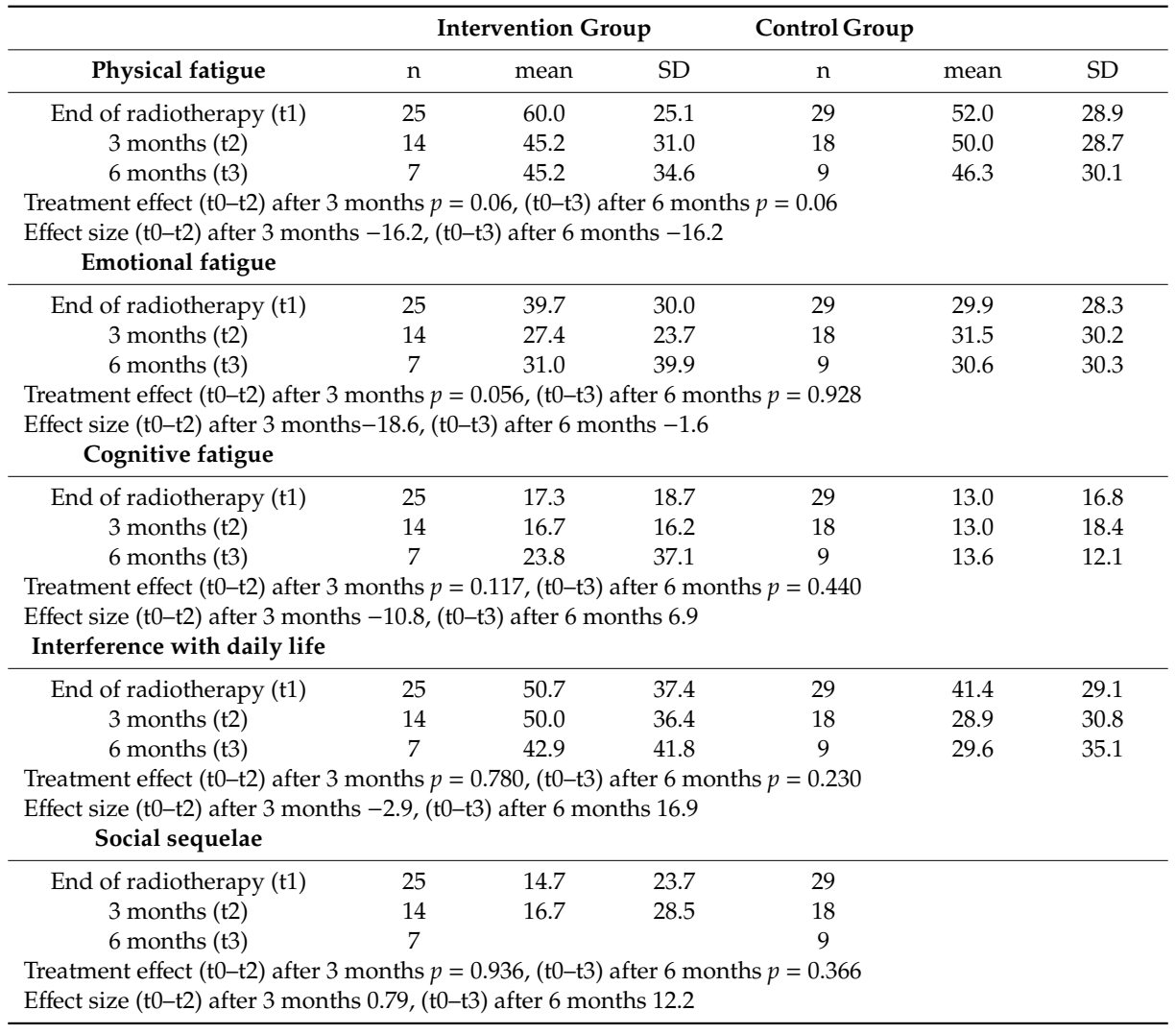


Table 6. Effects on emotional distress according to FBK-R10 questionnaire.

\begin{tabular}{ccccccc}
\hline & \multicolumn{7}{c}{ Intervention Group } & Control Group \\
\hline FBK R10 & $\mathrm{n}$ & mean & SD & $\mathrm{n}$ & mean & SD \\
\hline Baseline (t0) & 26 & 23.7 & 8.5 & 29 & 17.9 & 9.2 \\
\hline End of radiotherapy $(\mathrm{t} 1)$ & 26 & 19.7 & 8.5 & 28 & 15.7 & 8.6 \\
\hline 3 months (t2) & 14 & 19.7 & 9.3 & 18 & 13.8 & 9.4 \\
\hline Treatment effect (t0-t2) after 3 months between the groups $p=0.235$, \\
\hline Effect size (t0-t2) after 3 months -4.1 \\
\hline
\end{tabular}

At all recorded time points, there were no significant QOL differences between groups, including pain characteristics, functional impairment, or psychosocial aspects ( $p>0.05$ for all). There were also no differences in all dimensions of fatigue between groups at each recorded time point $(p>0.05$ for all). Emotional distress was also similar $(p=0.235)$.

\section{Discussion}

The safety and feasibility of IPMT to better address pain, mobility, and QOL has heretofore never been prospectively addressed in patients with USM, who are at high risk of clinical exacerbation from such interventions. From this exploratory randomized study, the first of its kind to date, IPMT is potentially feasible for this high-risk population, with a clear majority of patients being able to complete the assigned regimen. During the observation period, in the INT group no serious side effects occurred requiring surgical intervention. However, the conclusion about the safety of IPMT can only be made with restrictions, given the high percentage of patients lost to follow-up or death.

It should first be addressed that this study was not powered to evaluate secondary endpoints such as pain response, bone density, pathologic fracture rate (which was imbalanced at baseline), and QOL. Hence, the statistically equivocal results in most of these parameters cannot be used to conclude that IPMT offers no benefit as compared to passive muscle relaxation. Rather, this study demonstrates its safety and feasibility, in efforts to further utilize this regimen in larger studies to adequately test other such endpoints.

This being said, pain response may be less impacted by IPMT and more by RT technique, as shown in promising randomized trials of ablative versus fractionated RT [31,32]. Herein, merging both 3DCRT and IMRT cases would not be expected to confound results, as both are fractionated and do not display differences in relevant endpoints. Bone density changes generally do not occur acutely and may also be impacted by other factors such as the short duration of follow-up herein.

The covariate analysis of pain response during $\mathrm{t} 0-\mathrm{t} 2$ showed no influence of OMED on VAS values in the INT group $(p=0.120)$. However, within the time period $\mathrm{t} 0-\mathrm{t} 2$, pain response within that group was clearly evident $(p=0.009)$. Similarly, examination of the supervised training units from $t_{0}$ to $t_{1}$ showed significant pain relief ( $p<0.001$, data not shown).

Despite the numerically increased initial fracture rate in the INT arm ( $\mathrm{n}=17,63 \%$ vs. CON: $\mathrm{n}=11,39 \%, p=0.079$ ) (which also had statistically higher SINS scores at baseline), no de novo fractures occurred. Only existing fractures showed a visible increase in INT (1/14 cases) and CON (3/18) $(p=0.419)$.

Future studies should stratify groups according to fracture rate at baseline or SINS score to avoid imbalance between groups. Importantly, the numerically higher pathologic fracture rate in INT at baseline did not translate to appreciable QOL changes, which is noteworthy. Lastly, it is also relatively 
intuitive that there were largely no significant QOL differences between arms, as QOL is a complex outcome that depends on a multitude of factors such as systemic disease status, ongoing therapies, and baseline functionality. It is thus likely that effects on QOL by IPMT (if present) would be blurred between cohorts based on other factors known to contribute to QOL.

The utility of this investigation impacts future studies in patients with spinal metastases. Historically, patients with stable spine metastases were often restricted from such activities, with even tighter restrictions in USM cases. In the more recent era, many protocols do not specify whether these exercise regimens are allowed. For instance, the RTOG 0631 protocol does not make a specific recommendation on this matter. Although that study pertains to SBRT instead of a traditional 5-10 fraction regimen as utilized herein, further work must be done to verify whether IPMT is safe for well-selected USM cases undergoing SBRT (recognizing that many will not be able to receive SBRT for several reasons).

The difficulty of planning a fixed number of training sessions in the palliative setting is well acknowledged, and as a result there was no precedent to how many high-risk USM patients could complete these sessions. This was a major reason why this randomized trial was exploratory in nature and why formal power calculations could not be made. All patients herein experienced systemic progression at some point during follow-up, which (along with side effects of therapy in itself) often requires temporary or prolonged stationary accommodation and may not be conducive to continuing the training program.

In addition to the above, there are several limitations meriting elaboration. Along with the small sample sizes, short follow-up/patient survival, and single-center nature, studies of the palliative population encompass inherently heterogeneous patients, and the effect on subgroups thus cannot be reliably analyzed. This also makes the results difficult to extrapolate to other work, along with the fact that the particular assessment methods (e.g., VAS) and frequencies thereof may differ from other work, hence also limiting generalizability. Second, corticosteroid doses were not accounted for, which may impact pain levels and "pain flares". Third, reasons for opioid usage as well as subjective pain relief are inherently difficult to assess, and are known limitations of any palliative study despite the prospective nature. Fourth, because the patients were included with a Karnofsky index $>70 \%$, it may not necessarily include a representative population reflective of clinical practice. Nevertheless, these shortcomings do not diminish the requirement to construct similar randomized trials powered for other endpoints, especially given that the safety and feasibility of IPMT in the high-risk USM population has been supported by these randomized results.

\section{Conclusions}

IPMT is potentially feasible for high-risk USM patients. Future trials adequately powered for relevant endpoints are thus recommended.

Supplementary Materials: The following are available online at http://www.mdpi.com/2072-6694/11/11/1771/s1, Table S1: CONSORT 2010 checklist to reporting feasibility trial.

Author Contributions: H.R., F.R., J.W. and J.D. developed and planned this trial. F.R. and J.W. developed and conducted the individual training. T.B. is responsible for statistical considerations. T.S., V.V., R.F., I.S., T.B., S.A., T.R., N.H.N. and H.R. performed the examinations and RT supervisions. T.W. examined the stability of the spine. H.R. and T.S. made the data collection. A.-L.G. reviewed and edited the manuscript. All authors read and approved the final manuscript.

Funding: The authors received no specific funding for this study. The senior author (H.R.) had full access to the entire data of the study and had the final responsibility regarding the decision to submit for publication.

Acknowledgments: The authors thank all study participants for their great efforts.

Conflicts of Interest: The authors declare no conflicts of interest. 


\section{Abbreviations}

$\begin{array}{ll}\text { Anti-RANKL } & \text { Anti-Receptor Activator of Ligand } \\ \text { CON } & \text { Control group } \\ \text { CT } & \text { Computed tomography } \\ \text { CTCAE } & \text { Common Terminology Criteria for Adverse Events } \\ \text { CTV } & \text { Clinical target volume } \\ \text { EORTC } & \text { European Organization for Research and Treatment of Cancer } \\ \text { 3DCRT } & \text { Conventional 3D conformal radiotherapy } \\ \text { Gy } & \text { Gray } \\ \text { IC } & \text { Informed consent } \\ \text { IMRT } & \text { Intensity-modulated radiotherapy } \\ \text { INT } & \text { Intervention group } \\ \text { IPMT } & \text { isometric paravertebral muscle training } \\ \text { MRI } & \text { Magnetic resonance imaging } \\ \text { OMED } & \text { Oral morphine equivalent dose } \\ \text { OS } & \text { Overall survival } \\ \text { PTV } & \text { Planning target volume } \\ \text { QOL } & \text { Quality of life } \\ \text { RT } & \text { Radiotherapy } \\ \text { SBRT } & \text { stereotactic body radiotherapy } \\ \text { SIB } & \text { Simultaneously integrated boost } \\ \text { SINS } & \text { Spinal Instability Neoplastic Score } \\ \text { USM } & \text { Unstable spine metastases } \\ \text { VAS } & \text { Visual analog scale } \\ \text { VCF } & \text { Vertebral compression fracture } \\ \text { VMAT } & \text { Volumetric modulated arc therapy } \\ & \end{array}$

\section{References}

1. Wong, D.A.; Fornasie, V.L. MacNab I: Spinal metastases: The obvious, the occult, and the impostors. Spine 1990, 15, 1-4. [CrossRef] [PubMed]

2. Coleman, R.E. Clinical features of metastatic bone disease and risk of skeletal morbidity. Clin. Cancer Res. 2006, 12, 6243s-6249s. [CrossRef] [PubMed]

3. Fourney, D.R.; Frangou, E.M.; Ryken, T.C.; Dipaola, C.P.; Shaffrey, C.I.; Berven, S.H.; Bilsky, M.H.; Harrop, J.S.; Fehlings, M.G.; Boriani, S.; et al. Spinal instability neoplastic score: An analysis of reliability and validity from the spine oncology study group. J. Clin. Oncol. 2011, 29, 3072-3077. [CrossRef] [PubMed]

4. Weis, J.; Arraras, J.I.; Conroy, T.; Efficace, F.; Fleissner, C.; Gorog, A.; Hammerlid, E.; Holzner, B.; Jones, L.; Lanceley, A.; et al. Development of an EORTC quality of life phase III module measuring cancer-related fatigue (EORTC QLQ-FA13). Psycho-Oncology 2013, 22, 1002-1007. [CrossRef] [PubMed]

5. Moussazadeh, N.; Rubin, D.G.; McLaughlin, L.; Lis, E.; Bilsky, M.H.; Laufer, I. Short-segment percutaneous pedicle screw fixation with cement augmentation for tumor-induced spinal instability. Spine J. 2015, 15, 1609-1617. [CrossRef] [PubMed]

6. Foerster, R.; Bruckner, T.; Bostel, T.; Schlampp, I.; Debus, J.; Rief, H. Prognostic factors for survival of women with unstable spinal bone metastases from breast cancer. Radiat. Oncol. Lond. Engl. 2015, 10, 144. [CrossRef]

7. Versteeg, A.L.; van der Velden, J.M.; Hes, J.; Eppinga, W.; Kasperts, N.; Verkooijen, H.M.; Oner, F.C.; Seravalli, E.; Verlaan, J.J. Stereotactic Radiotherapy Followed by Surgical Stabilization Within $24 \mathrm{~h}$ for Unstable Spinal Metastases; A Stage I/IIa Study According to the IDEAL Framework. Front. Oncol. 2018, 8, 626. [CrossRef]

8. Sprave, T.; Hees, K.; Bruckner, T.; Foerster, R.; Bostel, T.; Schlampp, I.; El Shafie, R.; Nicolay, N.H.; Debus, J.; Rief, $\mathrm{H}$. The influence of fractionated radiotherapy on the stability of spinal bone metastases: A retrospective analysis from 1047 cases. Radiat. Oncol. Lond. Engl. 2018, 13, 134. [CrossRef]

9. Chow, E.; Harris, K.; Fan, G.; Tsao, M.; Sze, W.M. Palliative radiotherapy trials for bone metastases: A systematic review. J. Clin. Oncol. 2007, 25, 1423-1436. [CrossRef] 
10. Sze, W.M.; Shelley, M.; Held, I.; Mason, M. Palliation of metastatic bone pain: Single fraction versus multifraction radiotherapy-A systematic review of the randomised trials. Cochrane Database Syst. Rev. 2004, 2, CD004721. [CrossRef]

11. Schlampp, I.; Rieken, S.; Habermehl, D.; Bruckner, T.; Forster, R.; Debus, J.; Rief, H. Stability of spinal bone metastases in breast cancer after radiotherapy: A retrospective analysis of 157 cases. Strahlentherapie und Onkologie 2014, 190, 792-797. [CrossRef] [PubMed]

12. Foerster, R.; Habermehl, D.; Bruckner, T.; Bostel, T.; Schlampp, I.; Welzel, T.; Debus, J.; Rief, H. Spinal bone metastases in gynecologic malignancies: A retrospective analysis of stability, prognostic factors and survival. Radiat. Oncol. Lond. Engl. 2014, 9, 194. [CrossRef] [PubMed]

13. Foerster, R.; Hees, K.; Bruckner, T.; Bostel, T.; Schlampp, I.; Sprave, T.; Nicolay, N.H.; Debus, J.; Rief, H. Survival and Stability of Patients with Urothelial Cancer and Spinal Bone Metastases after Palliative Radiotherapy. Radiol. Oncol. 2018, 52, 189-194. [CrossRef] [PubMed]

14. Knols, R.; Aaronson, N.K.; Uebelhart, D.; Fransen, J.; Aufdemkampe, G. Physical exercise in cancer patients during and after medical treatment: A systematic review of randomized and controlled clinical trials. J. Clin. Oncol. 2005, 23, 3830-3842. [CrossRef]

15. Grote, M.; Maihofer, C.; Weigl, M.; Davies-Knorr, P.; Belka, C. Progressive resistance training in cachectic head and neck cancer patients undergoing radiotherapy: A randomized controlled pilot feasibility trial. Radiat. Oncol. Lond. Engl. 2018, 13, 215. [CrossRef]

16. Sandmael, J.A.; Bye, A.; Solheim, T.S.; Stene, G.B.; Thorsen, L.; Kaasa, S.; Lund, J.A.; Oldervoll, L.M. Feasibility and preliminary effects of resistance training and nutritional supplements during versus after radiotherapy in patients with head and neck cancer: A pilot randomized trial. Cancer 2017, 123, 4440-4448. [CrossRef]

17. Kampshoff, C.S.; van Dongen, J.M.; van Mechelen, W.; Schep, G.; Vreugdenhil, A.; Twisk, J.W.R.; Bosmans, J.E.; Brug, J.; Chinapaw, M.J.M.; Buffart, L.M. Long-term effectiveness and cost-effectiveness of high versus low-to-moderate intensity resistance and endurance exercise interventions among cancer survivors. J. Cancer Surviv. Res. Pract. 2018, 12, 417-429. [CrossRef]

18. Mijwel, S.; Jervaeus, A.; Bolam, K.A.; Norrbom, J.; Bergh, J.; Rundqvist, H.; Wengstrom, Y. High-intensity exercise during chemotherapy induces beneficial effects 12 months into breast cancer survivorship. J. Cancer Surviv. Res. Pract. 2019, 13, 244-256. [CrossRef]

19. Rief, H.; Forster, R.; Rieken, S.; Bruckner, T.; Schlampp, I.; Bostel, T.; Debus, J. The influence of orthopedic corsets on the incidence of pathological fractures in patients with spinal bone metastases after radiotherapy. BMC Cancer 2015, 15, 745. [CrossRef]

20. Rief, H.; Petersen, L.C.; Omlor, G.; Akbar, M.; Bruckner, T.; Rieken, S.; Haefner, M.F.; Schlampp, I.; Forster, R.; Debus, J.; et al. The effect of resistance training during radiotherapy on spinal bone metastases in cancer patients-A randomized trial. Radiother. Oncol. 2014, 112, 133-139. [CrossRef]

21. Rief, H.; Heinhold, M.; Bruckner, T.; Schlampp, I.; Forster, R.; Welzel, T.; Bostel, T.; Debus, J.; Rieken, S. Quality of life, fatigue and local response of patients with unstable spinal bone metastases under radiation therapy-a prospective trial. Radiat. Oncol. Lond. Engl. 2014, 9, 133. [CrossRef] [PubMed]

22. Rief, H.; Welzel, T.; Omlor, G.; Akbar, M.; Bruckner, T.; Rieken, S.; Haefner, M.F.; Schlampp, I.; Gioules, A.; Debus, J. Pain response of resistance training of the paravertebral musculature under radiotherapy in patients with spinal bone metastases-A randomized trial. BMC Cancer 2014, 14, 485. [CrossRef] [PubMed]

23. Rief, H.; Omlor, G.; Akbar, M.; Welzel, T.; Bruckner, T.; Rieken, S.; Haefner, M.F.; Schlampp, I.; Gioules, A.; Habermehl, D.; et al. Feasibility of isometric spinal muscle training in patients with bone metastases under radiation therapy-First results of a randomized pilot trial. BMC Cancer 2014, 14, 67. [CrossRef] [PubMed]

24. Welte, S.E.; Wiskemann, J.; Scharhag-Rosenberger, F.; Forster, R.; Bostel, T.; Bruckner, T.; Schlampp, I.; Meyerhof, E.; Sprave, T.; Nicolay, N.H.; et al. Differentiated resistance training of the paravertebral muscles in patients with unstable spinal bone metastasis under concomitant radiotherapy: Study protocol for a randomized pilot trial. Trials 2017, 18, 155. [CrossRef]

25. Taneichi, H.; Kaneda, K.; Takeda, N.; Abumi, K.; Satoh, S. Risk factors and probability of vertebral body collapse in metastases of the thoracic and lumbar spine. Spine 1997, 22, 239-245. [CrossRef]

26. Ryu, S.; Pugh, S.L.; Gerszten, P.C.; Yin, F.-F.; Timmerman, R.D.; Hitchcock, Y.J.; Movsas, B.; Kanner, A.A.; Berk, L.B.; Followill, D.S.; et al. RTOG 0631 phase 2/3 study of image guided stereotactic radiosurgery for localized (1-3) spine metastases: Phase 2 results. Pract. Radiat. Oncol. 2014, 4, 76-81. [CrossRef] 
27. Milano, M.T.; Constine, L.S.; Okunieff, P. Normal tissue tolerance dose metrics for radiation therapy of major organs. Semin. Radiat. Oncol. 2007, 17, 131-140. [CrossRef]

28. Chow, E.; Nguyen, J.; Zhang, L.; Tseng, L.M.; Hou, M.F.; Fairchild, A.; Vassiliou, V.; Jesus-Garcia, R.; Alm El-Din, M.A.; Kumar, A.; et al. International field testing of the reliability and validity of the EORTC QLQ-BM22 module to assess health-related quality of life in patients with bone metastases. Cancer 2012, 118, 1457-1465. [CrossRef]

29. Escalante, C.P. Treatment of cancer-related fatigue: An update. Support. Care Cancer 2003, 11, 79-83.

30. Book, K.; Marten-Mittag, B.; Henrich, G.; Dinkel, A.; Scheddel, P.; Sehlen, S.; Haimerl, W.; Schulte, T.; Britzelmeir, I.; Herschbach, P. Distress screening in oncology-evaluation of the Questionnaire on Distress in Cancer Patients-short form (QSC-R10) in a German sample. Psycho-Oncology 2011, 20, 287-293. [CrossRef]

31. Sprave, T.; Verma, V.; Forster, R.; Schlampp, I.; Bruckner, T.; Bostel, T.; Welte, S.E.; Tonndorf-Martini, E.; Nicolay, N.H.; Debus, J.; et al. Randomized phase II trial evaluating pain response in patients with spinal metastases following stereotactic body radiotherapy versus three-dimensional conformal radiotherapy. Radiother. Oncol. 2018, 128, 274-282. [CrossRef] [PubMed]

32. Sprave, T.; Verma, V.; Forster, R.; Schlampp, I.; Bruckner, T.; Bostel, T.; El Shafie, R.A.; Nicolay, N.H.; Debus, J.; Rief, H. Quality of Life Following Stereotactic Body Radiotherapy Versus Three-Dimensional Conformal Radiotherapy for Vertebral Metastases: Secondary Analysis of an Exploratory Phase II Randomized Trial. Anticancer Res. 2018, 38, 4961-4968. [CrossRef] [PubMed]

(C) 2019 by the authors. Licensee MDPI, Basel, Switzerland. This article is an open access article distributed under the terms and conditions of the Creative Commons Attribution (CC BY) license (http://creativecommons.org/licenses/by/4.0/). 